\title{
Reform Strategies on Universities Physical Education in the Background of Quality Education
}

\author{
Fengcheng Tang \\ College of Education and Sports, Bohai University, Jinzhou, 121013, China \\ 1106108759@qq.com
}

Keywords: quality education; universities; physical education; reform strategies

\begin{abstract}
According to the status quo of higher education and the requirement of quality education, this paper analyzes the status and function of physical education in quality education, points out the serious consequences of neglecting the quality of physical education in universities, and puts forward the reform strategies of universities' physical education under the background of quality education. The specific strategies include: constantly enrich the content of physical quality education, fully reflect the essential characteristics of quality education, innovative teaching model to meet the needs of future career, science and technology into the campus quality education, fully learn from foreign advanced physical education ideas, build a vibrant quality education system of physical education and the intuition of physical education under modern educational technology.
\end{abstract}

\section{Introduction}

School education, in the realization of quality education, in the process of improving the national physique has an irreplaceable role. University students should not only have excellent skills, but also should have high overall quality, must accept comprehensive quality education, so as to improve physical fitness, enhance the psychological affordability and intelligence level. In the process of all-round implementation of quality education, physical education plays a pivotal role. The traditional Physical teaching mode is far from the requirement of quality education, which is not in line with the development direction of modern vocational education, which is not conducive to cultivating students' professional accomplishment and does not meet the needs of professional talents training. Therefore, we must take the requirements of comprehensive quality education as the starting point in the current socio-economic environment, so as to strengthen the students' physique as the task, aiming at establishing the lifelong physical concept of students, focusing on cultivating students' professional quality of physical education, from the reality of universities' situation, the implementation of all-round reform of physical education for the healthy development of higher education service.

\section{Position and Function of Physical Education in Quality Education}

Physical education is an important part of quality education. It is a purposeful, planned and organized educational activity process that comprehensively develops the body, strengthens the students' physique, imparts the knowledge and skills of the sports, improves the level of the sports technology and fosters the moral and the volitional quality. The status and function of physical education in quality education are reflected in the following aspects:

(1) Physical education is an important way to achieve quality education. The basic purpose of the implementation of quality education is to cultivate students into the needs of the socialist modernization drive, all-round development talents of "moral, intellectual, physical, sound, aesthetics, labor". Physical education and a variety of sports and cultural activities to provide students with the opportunity to show their talents and improve themselves, promote the comprehensive development of cognition, emotion and skills, shaping students' behavior, quality, personality, emotion and interest, not only enhance students' physical and mental health, improve 
the physical quality, but also can carry out effective ideological and moral education, the development of intelligence, improve the psychological quality, cultivate sentiment, develop personality, promote the comprehensive development of students, and achieve an important way to achieve quality education.

(2) Physical education as an important carrier of cultivating students' ideological and moral qualities. Students in physical exercise, withstand certain physiological load and psychological load, overcome the conditions of objects and natural difficulties of conditions, adjust the relationship between people and people, people and objects, people and space-time. Sports competition is the ideological and moral character in the body, is a subtle process. Sports activities cultivate students "tenacious struggle and solidarity cooperation", extracurricular activities cultivate students "happy mood and cultivate sentiment", physical education class cultivate students "solidarity cooperation and excellent style of study", watch sports events to cultivate students "patriotism and national honor." Through the physical education strengthen the ideological structure of students, not only cultivate the moral quality, but also cultivate the ideological sentiment.

(3) Physical education is an effective mean to improve the physical quality of students. Students' physique is the national wealth, the physical quality of students is the relationship between the state and the future of the nation's major events, but also healthy growth and the foundation of happy life. With the improvement of people's living standard, sports consciousness is relatively lower, the physical condition of students is also worse than before. School physical education should enhance students' physical quality as an important task, promote the healthy development of students' physical function, improve students' basic activities, enhance students' immunity and self-control ability to the environment, and help students master the scientific exercise in practice, the fundamentally way to improve the physical quality of students for the future work and life lay a solid foundation.

(4) Physical education is the driving force to promote students' intellectual development. Physical education and intellectual education are inseparable, both of which are interrelated and interact. Experiments show that people who often participate in physical exercise, the acceptance of learning is better than average people. Physical education is an important mean of direct intellectual development, strong physique of students is conducive to study of culture of science and intellectual development. Intelligence development is mainly through the cultivation of observation, memory, thinking, imagination, logical judgment, practical ability, coordination ability and so on. Physical education as an educational and training exercise, in the process of imparting knowledge, cultivating skills and enhancing physical fitness, always run through these abilities. In the field of education, make full use of physical education as a powerful mean to vigorously develop students' intelligence.

(5) Lay foundation for the cultivation of students' lifelong sports conciousness. The "National Fitness Program" promulgated by the State Council advocates "lifelong sports" education, making sports an indispensable part of life. Lifelong sports should be part of lifelong education, improve the holistic social effects of lifelong education. School education is the basis of national education, through the school physical education, universal scientific fitness knowledge, establishing fitness is the most important part of the concept of healthy lifestyle, and train lifelong sports ideas. Lifelong physical exercise is integrated into the physical education, so that students master the general methods and skills of physical exercise, physical education is rationalization and scientization, stimulate students to participate in physical exercise, so as to participate in physical exercise for lifelong foundation.

\section{Serious Consequences of Neglecting Sports Quality Education in Universities}

University level is a critical period of physical development, the body of the function gradually mature, the body signs are gradually obvious. At present, many universities ignore the physical education of sports, leading students' interest in sports is not high, the body can not be significantly improved, serious lack of labor capacity, promote quality education constraints. Specifically, the neglect of the serious consequences of physical education is reflected in the following aspects: 
(1) Situation of declining in physical condition of university students is worrying. Since the recent period, many times the students in the violent physical activity appeared in the event of sudden death, life is irregular, lack of physical exercise directly lead to poor physical condition of universities students, school neglecting physical education indirectly led to the formation of the problem. The examination-oriented educational mechanism reduces the students' physical exercise time, affects the students' healthy development, increases the detection rate of overweight and obesity, reduces the immunity of the body, the serious decline of physical quality, and misses the opportunity to effectively promote the students' growth, health and enhance the students' physical health. Nearly $70 \%$ of university students did not meet the physical health standards, some university students only in the physical compliance test period participate in physical exercise. Heavy academic with employment, going abroad, postgraduate study and other aspects of the pressure, is the impact of university students exercise constraints. But neglecting physical education lead to reducing of physical activity, accelerating the decline in somatic function and physical health.

(2) Situation of the mental health of college students is worrying. Healthy psychology is the prerequisite for college students to accept ideological and political education and learn scientific and cultural knowledge. The mental health of college students has become a major problem in higher education. Physical education has the dual task of "fitness" and "conscience", which can affect the change of bad behavior, improve social adaptability, improve sensory sensitivity, improve self-improvement, promote mental relaxation, eliminate physical and mental disorders and get athletic skills. It is of great significance to promote the students' mental health, overcome the psychological disorder and improve the psychological quality, that is, the relationship between the mental health and the physical education. At present, many universities do not attach importance to physical education, lack of teaching staff, physical education, the level of attention, students in a state of coping, so that many students have a serious mental health problems, a direct impact on the individual development of students and higher education goals.

(3) Situation of serious reduction in student learning efficiency. Do well in work and rest, not only will not reduce but will help improve the quality of learning. In the spare time, appropriate physical exercise can promote the development of neuromuscular, promote intellectual development, the brain in a state of excitement, energetic, quick thinking, learning efficiency improved significantly. Many universities there is a "heavy main class, light physical education" phenomenon, that the physical education class will waste learning time, affecting academic performance, the trend of reducing physical education. Because of the lack of proper guidance on physical education, in spare time students like to surf the Internet, play games or read e-books, resulting in lack of sleep time, skin bleak, drooping spirit, seriously affect the learning efficiency. High-level students into practice or internship, it is the degree of physical education set aside, leading physical obesity and decline in quality, and they can not be competent to consume physical power more work.

\section{Reform Strategies on Universities Physical Education in the Background of Quality Education}

Universities in the training objectives highlight the professional and practical, physical education should implement the "people-oriented, health first, lifelong education, scientific development", the multiple guiding ideology, from the perspective of improving the quality of reform of the previous teaching system, experienced and scientific transferred to cultural and lifestyle changes, so that students have the professional needs of the practical sports knowledge, general physical fitness, professional special qualities and the ability of lifelong physical exercises. Specific strategies for physical education reform are as follows:

(1) Continue to enrich the content of physical education quality education. With the development of economic society and scientific technology, physical education plays an increasingly important role in quality education. In order to adapt to the development of higher education, the content of physical quality education should be continuously enrich and constantly give new vitality. The 
content of physical quality education is the full embodiment of individual quality in physical education. Physical quality education should be based on the contents of physical education, integration of physical psychology, physical politics, physical ideas, physical business, physical entertainment, physical aesthetic, physical technology and other aspects of education content, quality education content in physical quality education in the intersection constitute abundant physical quality education content.

(2) Fully embodies the substantive characteristics of quality education. Quality education has the characteristics of entire, developmental, subjective and comprehensive. Physical education teaching for all students, improve the physical quality of all students, so that each student into the material, so that each student have learned income; teaching process to enable students to acquire knowledge and skills on the basis of student potential and expertise Quality education is to carry forward the subject of education, physical education to respect the personality, to recognize the differences between students, so that students take the initiative to accept the knowledge; physical education should not only improve the physical fitness of students, but also improve the quality of students, promote students' ideological, moral and the comprehensive development of life skills.

(3) Innovative teaching model meet future career needs. Constructing the "Two - stage" physical education teaching model suitable for the characteristics of universities. The first stage of the first year of university students using "sports skills" physical education model, the teaching process is divided into "perception - understanding - consolidation - application" and several stages, through the study of sports technology, master the purpose of motor skills. The second stage for the second year of college students using the "selective system" physical education model, students according to their hobbies can choose a number of sports, teachers explain the basic unit, students through extracurricular practice strengthen the level of skilled to lay the foundation for lifelong physical exercise.

(4) Scientific and technological physical education into the campus quality education. Scientific and technological physical education is not through the body directly against, but the use of specific knowledge, skills and technology content of higher equipment, reflecting the technical level of physical activities. Scientific and technological physical education can be combined with the knowledge of various disciplines to promote students' aerobic capacity, with physical fitness, improve the overall quality and promote the development of innovative ability, the education sector and school leaders understand the scientific and technological physical education in the training of students comprehensive ability. the unique role of science and technology find a combination of scientific and technological physical education and quality education, combined with the professional characteristics of university students choose the appropriate science and technology sports, science and technology play a unique role in the fitness while developing intelligence and improve professional skills.

(5) Fully learn from foreign advanced physical education ideas. Under the new situation, we must seek a road of innovation with the characteristics of international vocational education and vocational education in China. The educational thoughts of all countries in the world, including "lifelong sports, great sports, active sports, learning to survive and care" and so on, provide abundant nutrition for our country's physical education and guide the healthy development of our country's physical education. The further integration of school sports has created a good ideological condition. It is necessary to pay attention to the improvement of students' physical and athletic skills, but also develop students' sports awareness, sports habits and attitude towards life. Dealing with the relationship between sports and health, sports and physical and mental characteristics of students with the organic combination. The past single exercise skills with learning-based learning goals, into emphasis on learning attitude, emotion and cognition, and format the correct values.

(6) Build vibrant sports quality education system. The educational system is an orderly combination of various educational elements, with the rational allocation of educational resources, stimulate educational creativity and solve the difficult problems in education and so on. The goal of college physical education teaching innovation should be mainly embodied as "four studies", that is, learn to exercise, master all kinds of sports skills; learn to live, the movement will penetrate into 
daily life; learn to develop, in lifelong sports and sunshine sports development character; learn to be a man, establish good interpersonal relationship and the spirit of sports ethics and cooperation. In view of the innovation goal, the sports quality education system should take the health first as the core, take the happy sports and the successful sports as the means, take the sun sports and the lifelong sports as the premise, take the sun sports and the happy sports as the guarantee to the lifelong sports and the successful sports oriented, and promote the overall quality of students to improve.

(7) Strengthen the modern education technology under the visualization of physical education. According to the law of things cognition, intuition is an effective way to carry out physical education. Image demonstration is one of the most common visual teaching methods in physical education. Students use the image of teachers to observe the image of the image, so that students can master sports knowledge, skills and technology as soon as possible. Modern education technology to multimedia as the surface, multimedia with sound, color, shape, image, map, text and other three-dimensional characteristics, compared to the traditional sports teacher demonstration more interesting and normative, more easily accepted by students. But the physical education teacher demonstration also has the advantage of multimedia can not match, therefore, make full use of modern educational technology with teachers, demonstration and guidance on the scene, is the best way of physical education.

\section{Conclusion}

Through in-depth research and analysis, from the actual situation, put forward the quality of education under the background of universities physical reform, all-round strategies for the new era of higher talent training, put forward specific recommendations and operational programs. The application of research results in this paper has a positive effect on promoting the development of quality education, cultivating qualified senior professional and technical talents, forming the ideology and behavioral habit of "health first, lifelong sports".

\section{References}

[1] Z. H. Zhu, "Research on the application of inquiry teaching in higher vocational physical education," Chinese Education Journal, vol. 36, no. 1, pp. 202-203, 2013.

[2] J. G. Zhang, X. Zhao, "The present situation and innovation of cultural quality education in higher vocational colleges," Chinese vocational and technical education, vol. 22, no. 11, pp. 73-75, 2014.

[3] M. Y. Wu, "School physical education and quality education: Comment on 'modern Chinese physical education theory research'," Contemporary Education Sciences, vol. 30, no. 19, pp. 74-74, 2015.

[4] L. Zhang, C. H. Xu, "How to carry out the idea of quality education in PE Teaching," Journal of Inner Mongolia Normal University(Educational Science), vol. 27, no. 12, pp. 163-164, 2014.

[5] X. Y. Ni, "Research on creative ability of quality education in higher vocational colleges," Education and Vocation, vol. 99, no. 15, pp. 43-45, 2015.

[6] J. H. Xia, "Research on integrating science and technology sports into campus quality education: Take Ningbo as an example," Zhejiang Sports Science, vol. 35, no. 6, pp. 88-90, 2013.

[7] Y. L. Zhang, "Strategy of physical education reform in higher vocational colleges under the concept of quality education," Contemporary sports science and technology, vol. 5, no. 28, pp. 106-107, 2015.

[8] L. S. Zhang, "Thinking of infiltrating vocational psychological quality education in higher vocational physical Education," Education and Vocation, vol. 99, no. 11, pp. 118-120, 2015. 